\title{
Living With and Beyond Cancer: New Challenges
}

\author{
Neel Bhuva, Sonia P. Li and Jane Maher \\ Mount Vernon Cancer Centre, Northwood, Middlesex,
}

UK

\section{Introduction}

'An illness in stages, a very long flight of steps that led assuredly to death, but whose every step represented a unique apprenticeship. It was a disease that gave death time to live and its victims time to die, time to discover time, and in the end to discover life.' Hervé Guilbert

The incidence of cancer is increasing with most current published statistics suggesting that approximately 300,000 new cases are being diagnosed annually in the UK. 1 in 3 will develop cancer during their lifetime. However, despite the incidence of cancer rising by almost $25 \%$ in the last 30 years, mortality rates have fallen by almost $20 \%$ in the same time period. In the UK, the overall cancer mortality rate in 2008 stood at just over 150,000 (Cancer Research UK, 2010). At present it is thought that two million people have cancer in the UK and as survival rates continue on an upward trend, this figure will only continue to rise (Table 1, Figures 1 and 2). This means that more and more people are living with or beyond a diagnosis of cancer especially with improving cure rates. Cancer is no longer a death sentence for an increasing number of patients.

\begin{tabular}{|c|c|c|c|}
\hline & UK & \% & ENGLAND \\
\hline Total & $2,000,000$ & 100 & $1,670,000$ \\
\hline Male & 800,000 & 40 & 670,000 \\
\hline Female & $1,200,000$ & 60 & $1,000,000$ \\
\hline Age & & & \\
$0-17$ & 16,000 & 0.8 & 13,000 \\
\hline $18-64$ & 774,000 & 38.7 & 645,000 \\
\hline $65+$ & $1,210,000$ & 60.5 & $1,010,000$ \\
\hline Breast & 550,000 & 28 & 460,000 \\
\hline Colorectal & 250,000 & 12 & 210,000 \\
\hline Prostate & 215,000 & 11 & 180,000 \\
\hline Lung & 65,000 & 3 & 54,000 \\
\hline Other & 920,000 & 46 & 766,000 \\
\hline
\end{tabular}

Kings College London, MacMillan Cancer Support and National Cancer Intelligence Network,Cancer Prevalence in the UK, 2008

Table 1. Number of people living in the UK and England who have had a cancer diagnosis 
Relative five-year estimates based on survival probabilities observed during 2000-2001, by sex and site, England and Wales

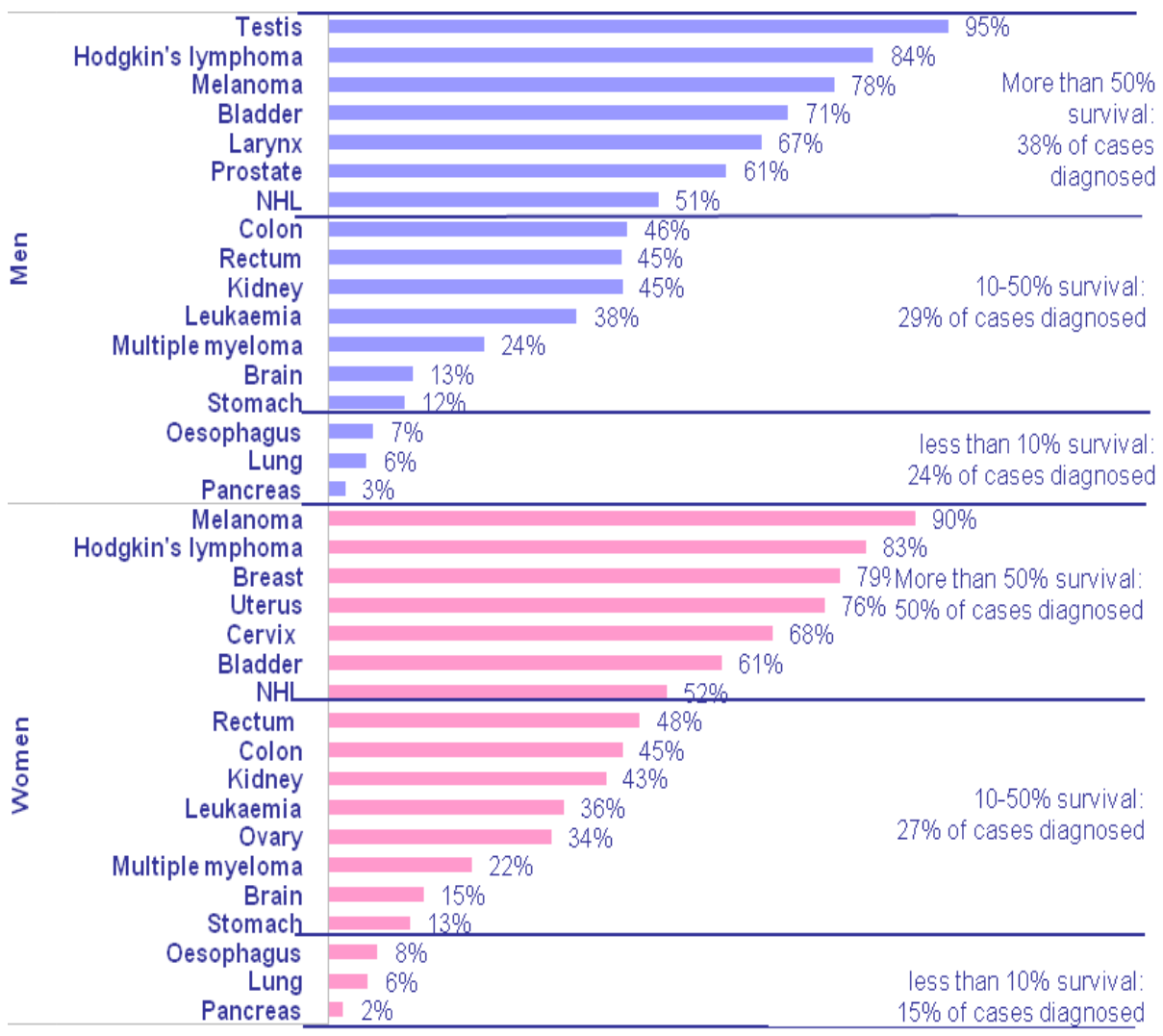

Five-year relative survival

${ }^{1}$ Cancer Research UK, Cancer Stats

${ }^{2}$ Coleman MP et al. Trends and socioeconomic inequalities in cancer survival in England and Wales up to 2001.Br J Cancer, 2004. 90(7): 1367-73

Fig. 1. Relative 5-year survival rates ${ }^{1,2}$ 


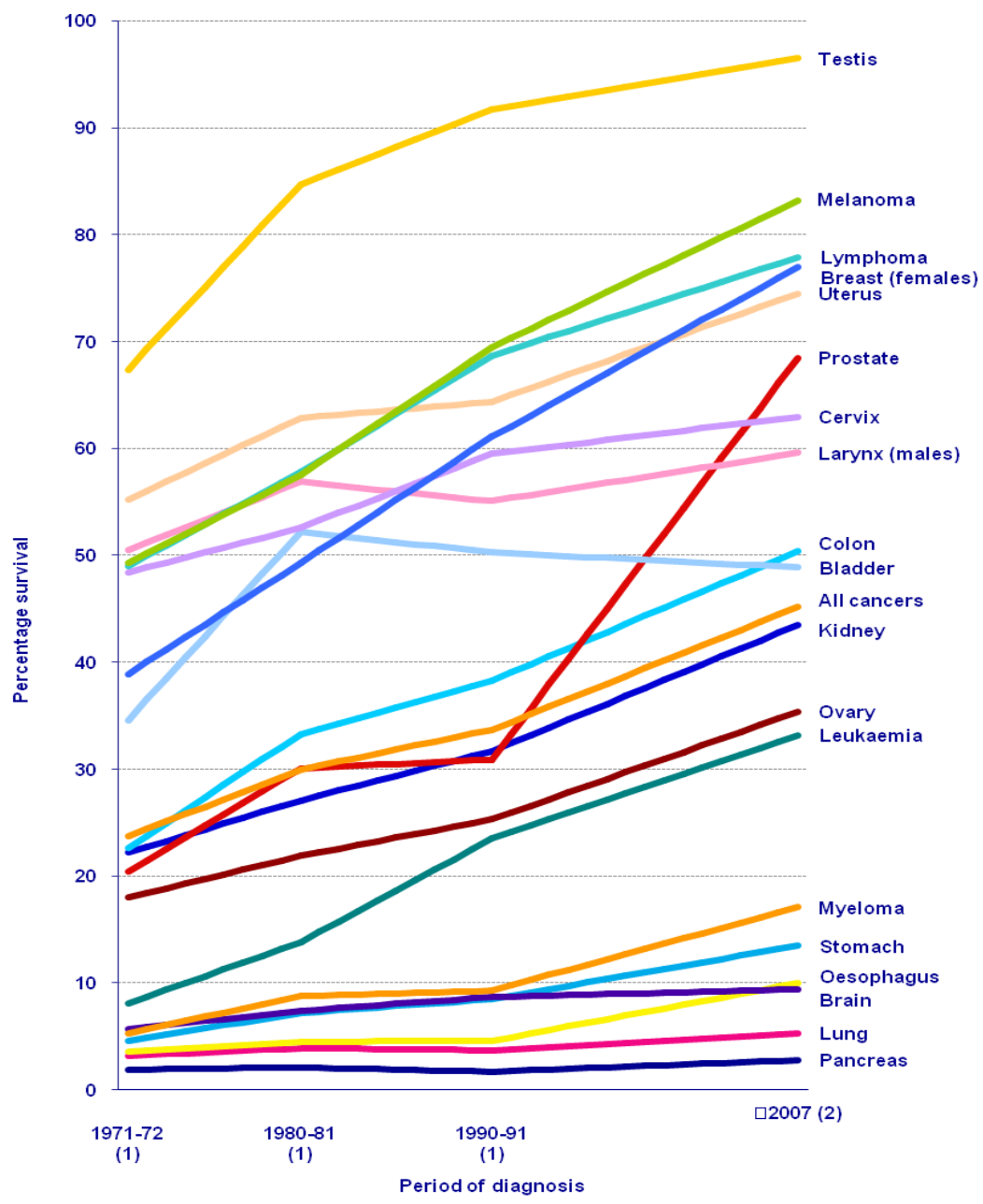

(1) 1971-1991 Cohort Analysis - actual survival, (2) 2007 Hybrid Analysis - predicted survival 1Coleman MP et al. Research commissioned by Cancer Research UK, 2010

Fig. 2. Ten year relative survival (\%), adults (15-99 years), selected cancers, England and Wales: survival trends for selected cancers 1971-2007

In fact, survival is increasing and we extrapolate that by 2030 the number of cancer survivors will rise to 4 million (Armes et al., 2009). For the most part, these individuals remain well and healthy but a small number will experience changes to their well-being. As more people live with cancer the proportion of this latter group will go up as well. Crosssectional studies of populations with chronic illnesses reveal similar health and wellness profiles to populations in whom cancer is present but not active (Birgisson et al., 2008) This suggests that we are living long enough to develop conditions related to the treatment as well as the cancer itself and that we must focus on the quality of survival after different treatments. 
A quarter of cancer patients will experience long-term effects that compromise their quality of life. These effects may manifest up to 10 years later and range from minor ailments in the majority to complex and debilitating problems for an unlucky few. Treatments now used to cure patients may no longer be considered ideal when treatment related adverse effects are taken into account and although most will be able to cope with minor conditions, a substantial minority will not. As a result, we must recognise and address the needs of these individuals. Early detection of symptoms, appropriate management and patient education are all key aspects to this. As curative approaches to different cancers become increasingly widespread, the focus needs to be more on quality of survival and reducing the disability associated with them. This is our challenge for the future.

At present it is estimated that almost half a million cancer survivors in the UK suffer from a chronic treatment related condition which impacts their quality of life. In the United States, a National Health Interview study (Hewitt et al., 2003) compared 5,000 cancer survivors with 90,000 people without any history of cancer. It found that cancer survivors were more likely to report being in poor health both psychologically and physically. As we move forward, this will translate into a huge burden on our health resources, especially in the primary care setting. These findings are mirrored by results of similar studies in the UK which have also highlighted the financial impact on cancer patients as a result of no longer being able to work or who are subject to extra costs incurred due to their treatment and/or long-term disability (Fobair, 2007; Macmillan Cancer Support, 2006; Yabroff et al., 2007). It is important therefore, that measures are put in place now to minimise this.

\section{Addressing the late effects of cancer treatment}

\subsection{Definition of late effects}

There is currently no agreed definition for the late effects of treatment with some differentiating between long term effects (those occurring during treatment and persisting after completion) and late effects (toxicities not apparent during primary treatment but manifesting some time later). However, the internationally accepted classification of adverse effects of treatment, the Common Toxicities Common Adverse Effects criteria (CTCAE) does not distinguish "acute" and "late" effects.

In response to this, the National Cancer Survivorship Initiative Late Effects workstream has proposed the following definition that "late effects are the long-term consequences of cancer and its treatment, including those which appear during, or soon after treatment, as well as those which appear months or years later".

These effects include:

- Heart (e.g. heart failure following anthracyclines and herceptin)

- Lungs (e.g. radiotherapy, bleomycin)

- Kidneys (e.g. cisplatin)

- Gastrointestinal tract (eg pelvic radiotherapy)

- Musculoskeletal system (eg amputations)

- Lymphatic system (eg lymphoedema)

- Brain (eg impact on cognition following chemotherapy or radiotherapy)

- Peripheral nerves (eg neuropathy related to platinum based drugs)

- Endocrine system (eg growth, fertility, thyroid deficiency, early menopause)

- Sexual interest and function 
- Genitourinary system (e.g. following pelvic radiotherapy)

- Second cancers (e.g. breast cancer following radiotherapy for Hodgkin's disease)

- Emotional impact of long-term and late effects of cancer and its treatment.

\subsection{Treatment related late effects}

Surgery, chemotherapy and radiotherapy all have consequences, which may become apparent immediately or after several years. These include urinary, bowel and sexual dysfunction, neuropathy, cardiovascular and endocrine abnormalities. Those treated as children are at greater risk of complex and inter-related issues arising after a substantial period of time with the risk of a second malignancy becoming an increasingly real threat. Surgery and radiotherapy can result in significant ongoing co-morbidities. For those patients, for example, who underwent bowel resections, gastrointestinal sequelae of treatment can be severe and most often manifest as loose stool and incontinence. Pelvic radiotherapy has led to increasing cure rates of many cancers but the incidence of long term gastrointestinal problems is even higher (Flentje \& Guckenberger, 2006) than with surgery including problems such as urgency, flatulence, abdominal pain and intermittent or regular soiling. Studies report that only a third of patients report normal or good bowel function (Lundby et al., 2005; Marijnen et al., 2005). Despite this, only few gastroenterologists feel adequately trained to deal with such side effects of treatment.

Management of long-term gastrointestinal effects is poorly represented in the literature with little research in the field. Such problems are often very embarrassing to patients and therefore under-reported. Patients may feel that nothing can be done and physicians may not encourage patients to discuss these issues due to their minimal experience in dealing with them (Andreyev et al., 2003a, Andreyev et al., 2003b; Putta \& Andreyev, 2005). Such patients inevitably withdraw from social interaction from fear of uncontrollable symptoms (Faithfull, 1995). It is not just bowel related difficulties that these patients face but also urological and sexual dysfunction. Furthermore, fractures, neurological issues and thromboembolic phenomena are also seen, although less frequently. 17,000 patients a year are treated with radiotherapy to the pelvis with almost 80,000 survivors of this treatment in the UK. Almost half of these individuals feel that sequelae of treatment has had an impact on their quality of life with 27,000 describing this impact as moderate to severe. These figures are probably an underestimation, particularly as follow-up times for most studies preclude the true magnitude of late effects. Furthermore, few patients freely admit to diarrhoea or incontinence unless directly asked and therefore questionnaires may be too insensitive and not reproducible. The British Society of Gastroenterology is due to publish guidelines on the management of treatment-related late effects this year.

The formation of RAGE (Radiotherapy Action Group Exposure) campaign was to address and improve conditions for patients with breast cancer who experienced late radiation injury as a consequence of radiotherapy at a time when there were no national standards in the United Kingdom. Although radiation damage is relatively rare, serious injuries such as those to the brachial plexus nerves causing weakness of the ipsilateral shoulder, arm and hand and vascular compromise have been reported. Less serious consequences such as rib fractures and skin discoloration may also arise. However, with many women now alive more than a decade after their diagnosis, the consequences of treatment of radiotherapy are becoming an increasing reality and a burden. Macmillan Cancer Support UK have focused on six main areas in response to RAGE (Hanley \& Staley, 2006). 
1. The development of a national register of consequences of treatment.

2. The improvement of communication between primary and secondary care.

3. Increasing the support to patients by providing information and assistance to patients in understanding the potential changes in their own health after treatment and on when to seek help.

4. The development of easily accessible pathways to access multidisciplinary specialist expertise to patients with late side-effects.

5. The development of an expert patient program for chronic treatment related conditions.

6. The development of innovative commissioning models to help patients get the care they need.

It is not just surgery and radiotherapy that have consequences. Chemotherapy is toxic and mutagenic, causing short-term multi-organ toxicity and increasing the risk of secondary malignancy. Two of the biggest hurdles women with breast cancer face after treatment is the fatigue associated with the cumulative effect of months of treatment and the after-effects of chemotherapy, together with mild cognitive impairment such as memory deficits, often termed "chemobrain" (Tannock et al., 2004). Furthermore, ongoing treatments in patients with breast cancer such as endocrine therapies which are often continued for at least five years, can affect recovery, leaving patients with physical problems such as fatigue, hot flushes, weight gain, joint pains and muscle aches. Tamoxifen can cause endometrial hyperplasia and increase the risk of endometrial malignancy. Osteoporosis and arthalgia are potential adverse effects that can arise from the use of aromatase inhibitors. Although hospital based follow-up systems have been developed to help monitor and detect any late toxicities, it may actually be more effective to educate patients to recognize problems. It is also important that adaptive strategies are discussed with patients in order to help them cope with these side-effects.

\subsection{Complex treatment related late effects}

A small proportion will suffer from severe or complex problems associated with treatment requiring specialist input. Some of these could be avoided through the prompt recognition and correct management of symptoms thereby avoiding the potential distressing complications resulting from inappropriate procedures. Occasionally, there may be people with unexpected effects associated with treatments which may require a national process of recall, reassessment and commissioning of new services. An example of this is in the group of young patients who received "Mantle" field radiotherapy for Hodgkin's lymphoma which was subsequently associated with a high incidence of breast cancer. There are challenges both in identifying which patients should be recalled as well as how to link them to appropriate specialist multidisciplinary management.

\subsection{Secondary malignancies}

Secondary malignancies can develop as a consequence of primary treatment, in particular, for patients who received treatment for a childhood cancer. Treatment for Hodgkin's lymphoma is associated with secondary leukaemia and breast cancer. Secondary malignancies are the sixth most common cancer in the USA (after skin, breast, prostate, bowel and lung cancers) and a cancer survivor has twice the risk of a comparable individual without cancer of developing another primary. This makes it all the more important to educate patients and GPs about potential warning signs of another malignancy. 


\section{Surviving cancer}

Mullan (1985) in his seminal paper "Seasons of Survival" describes the evolving process of surviving cancer as beginning from diagnosis and involving the following 3 phases (Mullan, 1985):

- Acute Survival: the first year, recovery from the diagnosis and treatment.

- Extended Survival: five years after treatment.

- Permanent Survival: the long term.

The acute phase is particularly difficult with a multitude of physical and psychosocial issues that patients may face. The organic side effects of treatment are the first hurdle but with the completion of treatment, a whole host of unexpected emotions such as uncertainty, fear of recurrence and abandonment may surface (Pelusi, 1997). There are huge psychological hurdles that patients may need to deal with; a sustained mortal threat, unrelenting personal and domestic turmoil, long difficult medical treatments and a prolonged uncertainty about the future. At this point, patients may find that they need to face up to the realities from being an ill person to being a survivor, from feeling time is unlimited to a having finite lifespan and from being fully able to living with a disfigurement or disability. Returning to work can be a huge physical and mental challenge. Patients' view of themselves may have changed and side effects of treatment such as mood changes and hot flushes may make social interaction difficult (Charmaz, 1983; Wyatt 1996). Hospitals form a protective bubble, having become a familiar and comfortable place in which patients often feel a sense of togetherness and reassurance. The sudden foray into the world outside can therefore be lonely and unpredictable. As time passes, most begin to feel a sense of security return and find that their health becomes more predictable. However a significant proportion, approximately 20-30\%, will still suffer from continuing distress (Absolom, 2009; Foster, 2009) and will require increasing support in the community. Predictors of persistent, moderate and severe problems with daily living may include a high level of unmet physical needs, fear of recurrence, stress of looking after a family and increasing imposition on their health by unrelated co-morbidities or iatrogenic interventions.

Extended survival is the period where active hospital based surveillance is the mainstay of follow-up. However, these first five years after treatment has ended also represent the period of highest recurrence risk. Reduced levels of activity and less acute symptomatology may persist which over time could erode into the ability to enjoy life and maintain relationships. For example, menopausal symptoms are experienced by $70 \%$ of patients treated for breast cancer and can persist for several years impacting severely on quality of life (Carpenter \& Andrykowski, 1999; Fenlon et al., 2009; Hunter et al., 2004; Walker et al., 2007). An online survey found that over $30 \%$ of breast cancer survivors stopped adjuvant aromatase inhibitor therapy due to their side effects (Zivian \& Salgado, 2007). Long term sexual difficulties are also a challenge, with loss of libido, decreased orgasm and physical difficulties (retrograde ejaculation and impotence in men on GHRH antagonists, dyspareunia in women on endocrine therapy). Such issues are often considered taboo or difficult to discuss with medical professionals. Many more women are being diagnosed at a younger age due to screening programmes and therefore wish to maintain fertility. Access to fertility preserving facilities is variable and simply potentiates an already sensitive issue (Amir \& Ramati, 2002; Bloom et al., 2004; Broeckel et al., 2002).

Permanent survival refers to treatment related problems that emerge years or decades after the initial diagnosis. This is most apparent in children, a group in whom, as cancer treatment has become more successful, has an increasing number of survivors developing treatment 
related sequelae such as premature ischaemic heart disease and dyslipidemia after radiation to the heart. Ominously, a similar pattern is developing in adults also. Survivors of breast cancer who were given radiotherapy at a relatively young age are now demonstrating an increased incidence of cardiac problems with age. Despite evidence suggesting that these patients are also at a significantly higher risk of recurrence of a second primary later on in life, many are not receiving more intense screening than the normal population.

\section{Responding to the changing cancer story: Focus on the future}

In the past and even in the present, cancer services continue to focus predominantly on the acute recovery phase with little emphasis on a five or even ten-year support plan. The first year after treatment is merely the 'tip of the iceberg' and it is crucial that our approach to treating cancer is more visionary and holistic, viewing cancer as a chronic illness rather than an acute condition.

A recent UK survey concluded that at present, follow-up is primarily a check for signs of recurrence or spread (Theis et al., 2010), and checking for recurrence is perceived by the patient as the most important reason for engaging in follow-up. Several studies are currently underway exploring different follow-up methods. What is clear, particularly in the case of colorectal cancer, is that more intense follow-up in the first two years does improve survival, as evidenced by five out of six recent systematic reviews (Figueredo et al., 2003; Richard \& Mcleod, 1997; Rosen et al., 1998, Tjandra \& Chan, 2007). However, what is not clear is which aspects of follow-up are associated with this. Within the NHS in the UK, consensus meetings have concluded that many follow-up appointments are not required and for many, the common cancers signs of recurrence are as easily and reliably detectable by the patients as they are by expensive surveillance investigations. As long as there is a robust method of feedback to the clinician, i.e. through a specialist nurse, unnecessary appointments can be avoided thus releasing resources and achieving a system, which is more geared to focus on assessment of the cancer, rehabilitation and dealing with the emotional, psychosocial and financial burdens of patients. We need a more bespoke service tailored to the needs of the individual person rather than a 'one size fits all' approach.

The English National Cancer Survivorship Initiative (NCSI) aims to address this issue and provides a vision for better care and support for cancer survivors in the UK. It highlights the importance of recognition and self-management of ongoing problems and raises awareness of the longer-term consequences of cancer (DH, Macmillan Cancer Support \& NHS Improvement, 2010). The NCSI is a partnership between Macmillan Cancer Support and the Department of Health and sets out five key shifts in its Vision document of January 2010, outlining ways to assess need, plan care and support cancer survivors to recognise and manage ongoing problems:

- A cultural shift with greater focus on recovery, health and well-being after cancer treatment.

- A shift towards personalized assessment, information provision and care planning.

- A shift towards support for self management.

- A shift from a single model of clinical follow-up to tailored support that enables early recognition and preparation for both the signs of further disease and the longer-term consequences of treatment.

- A shift towards using Patient Reported Outcome Measures as well as clinical measures. 
This should raise awareness and allow intervention to help deal with the longer term consequences of cancer treatment, including the recognition that survivors of cancer have particular risks in relation to unhealthy lifestyles. Some long term cancer survivors express a preference for hospital-based services including telephone based services and those who have experience of such services are generally very positive about them. Furthermore, as part of the National Cancer Survivorship Initiative, different ways to deliver after cancer treatment care such as "end of treatment care packages" including information about "what to expect", written care plans, description of symptoms indicating a need for tests, coping strategies and a variety of educational interventions are being investigated and these will be reported in 2011-12 to aid in the commissioning of new pathways.

If change is to be successfully implemented it will require coordination of services and teamwork between secondary care, primary care and the patients themselves. The transitions between the three phases of survivorship according to Mullan's model have been dubbed as 'teachable moments' (Denmark-Wahnefried et al., 20045). These are seen to be opportunities for giving information on health surveillance and healthy living. Cancer survivors are receptive to any initiatives that will improve their health, but many are not aware that lifestyle changes are especially important for them, given that they are at an increased risk of chronic illnesses and further malignant disease. Not only do we need to equip patients to know what symptoms to look for and when they require to be seen by a medical professional, but we must also unlock these gateways in order that they may benefit from programmes supporting lifestyle change, such as smoking cessation, weight loss and exercise.

Primary care will also need to play an increasingly important role. General practitioner should no longer see cancer in simple terms i.e. 'cured and back to normal' or 'incurable and terminal'. Many general practitioner have not received any training or education about the long-term consequences of cancer and its treatment and therefore may not always make the connection between a symptom or series of symptoms and past cancer treatment. Furthermore, in some cases, they may not view it as their responsibility to identify and manage these consequences. Progressive, complex problems related to rare conditions and/or obsolete treatments may often go unrecognised. Symptoms of all patients with a cancer history should be considered as possibly relating to that cancer. Furthermore, practices must employ up-to-date and accurate recording of patients so that previous cytotoxic or radiation treatments are highlighted on computer systems. Visual alerts can bring an individual's cancer diagnosis to the forefront of the primary care physician's mind during a consultation. The flow of information between oncologist and GP is vital with one of the mandates of the NCSI specifically addressing how this can be improved. GPs also need to be educated on being pro-active in asking about physical symptoms, such as those with heart disease, as well as providing and facilitating psychological support. It is crucial that GPs and patients are given access to freely available information regarding the long term sequelae of oncological treatments, and those patients identified as being at higher risk are more closely monitored and receive appropriate lifestyle advice.

\section{Transition}

The landscape of cancer treatment is changing. In today's world we do not just treat cancer we live with it. In tomorrow's world we will survive it. 
'Survival machines which can simulate (i.e.imagine) the future are one jump ahead of survival machines who can learn only by trial and error...'

Richard Dawkins

\section{References}

(2010) In: Cancer Research UK, Accessed 21 June 2010, www.info.cancerresearchuk.org/cancerstats/types/cervix/incidence.

Http://info.cancerresearchuk.org/cancerstats/types/breast/survival/index.htm\# depr

Absolom, K. et al. (2009). Follow-up care for cancer survivors: views of the younger adult. British Journal of Cancer, Vol.101, No.4, pp. 561-567

Amir, M. \& Ramati ,A. (2002). Post-traumatic symptoms, emotional distress and quality of life in long-term survivors of breast cancer: a preliminary research. Journal Anxiety Disorder, Vol.16, pp. 195-206

Andreyev, H.J.N. et al. (2003). GI symptoms developing after pelvic radiotherapy require gastronenterological review but is this happening in the UK? Clin Oncol, Vol.15, No.2, S12 (abstract)

Andreyev, H. et al. (2003). GI symptoms developing after pelvic radiotherapy require gastroenterological review. Gut Vol.52, supplement 1, A90

Armes, J. et al. (2009). Patients' supportive care needs beyond the end of treatment: aprospective and longitudinal survey. Clin Oncol, Vol.27, No.36, pp. 6172-6179.

Birgisson, H. et al., (2008). Late gastrointestinal disorders after recal cancer surgery with and without pre-operative radiation therapy. British Journal of Surgery, 2008, Vol.95, No.2, pp. 206-213.

Bloom, J.R. et al. (2004). Then and now: quality of life of young breast cancer survivors.Psycho-Oncology, Vol.13, pp. 147-160

Broeckel, J.A., et al. (2002). Sexual functioning in long-term breast cancer survivors treated with adjuvant chemotherapy. Breast Cancer Research and Treatment, Vol.75, pp. 241248

Carpenter, J.S. \& Andrykowski, M.A. (1999). Menopausal symptoms in breast cancer survivors. Oncology Nursing Forum, Vol.26, No.8, pp. 1311-1317

Charmaz, K. (1983). Loss of self: a fundamental form of suffering in the chronically ill. Sociology of HealthE Illness, Vol.5, No.2, pp.168-95

Demark-Wahnefried, W. et al. (2005). Riding the crest of the teachable moment: promoting long-term health after the diagnosis of cancer. Clin Oncol, Vol.23, No.24, pp. 58145830

DH, Macmillan Cancer Support and NHS Improvement. The National Cancer Survivorship Initiative Vision 2010. Available from http://www.dh.gov.uk/publications

Faithfull, S. (1995). 'Just grin and bear it and hope that it will go away': coping with urinary symptoms from pelvic radiotherapy. Eur J Cancer Care, Vol.4, No.4, pp. 158-165

Fenlon, D.R. et al. (2009). Menopausal hot flushes after breast cancer. Eur J of Cancer Care, Vol.18, No.2, pp. 140-148 
Figueredo, A. et al. (2003). Follow-up of patients with curatively resected colorectal cancer: a practice guideline. BMC Cancer, Vol. 3, pp. 26

Fobair, P. (2007). Oncology social work for survivors. Cancer Survivorship Today andTomorrow. Ed Patricia Ganz pub Springer pp. 114-121

Foster, C. et al. (2009). Psychosocial implications of living five years or more following a cancer diagnosis. A systematic review of the research evidence. Eur J. of Cancer Care, Vol.18, pp. 223-247

Guckenberger, M. \& Flentje, M. (2006). Late small bowel toxicity after adjuvant treatment for rectal cancer. Int J Colorectal Dis, Vol. 21, pp. 209-220

Hunter, M.S. et al. (2004). Menopausal symptoms in women with breast cancer: prevalence and treatment preferences. Psycho-Oncology, Vol.13, No.11, pp. 769-778

Lange, M.M. et al. (2007). Risk factors for faecal incontinence after rectal cancer treatment. $\mathrm{Br}$ Journal of Surgery, Vol.94, Ch.10, pp. 1278-1284

Lundby, L. et al. (2005). Long term anorectal dysfunction after postoperative radiotherapy for rectal cancer. Dis Colon Rectum, Vol.48, Ch.7, pp. 1343-1352

Macmillan Cancer Support. Cancer Costs 2006. www.macmillan.org.uk

Marijnen, C.A. et al. (2005). Impact of short term preoperative radiotherapy on health related quality of life and sexual functioning in primary rectal cancer: report of a multi-center randomized trial. Clin Oncol, Vol.23, Ch.9, pp. 1847-1858

Mullan, R. (1985) Seasons of survival: reflections of a physician with cancer. NEJM, Vol.313, pp. $270-273$

Pelusi, J. (1997). The lived Experience of Surviving Breast Cancer. Oncology Nursing Forum, Vol. 24, No.8, pp.1343-1353

Putta, S. \& Andreyev, H.J.N. (2005). Faecal incontinence - a late side effect of pelvic radiotherapy. Clin Oncol, Vol.7, Ch.6, pp. 469-477

Richard, C.S. \& Mcleod, R.S. (1997). Follow-up of patients after resection for colorectal cancer: a position paper of the Canadian Society of Surgical Oncology and the Canadian Society of Colon and Rectal Surgeons. Can J Surg, Vol.40, pp. 90-100

Rosen, M. et al. (1998). Follow-up of colorectal cancer: a meta-analysis. Dis Colon Rectum Vol.41, pp. 1116-1126

Tannock, I.F. et al. (2004). Cognitive impairment associated with chemotherapy for cancer: areport of a workshop. Clin Oncol, Vol.22, No.11, pp. 2233-2239

Theis, V.S. et al. (2010). Chronic Radiation Enteritis. Clin Oncol, Vol.22, pp. 70-83

Tjandra, J.J. \& Chan, M.K.Y. (2007). Follow-up after curative resection of colorectal cancer: a meta-analysis. Dis Colon Rectum, available from http://www.springerlink.com/content/r95uqr6x328u7130/

Walker, G., et al. (2007). Ear acupuncture for hot flushes--the perceptions of women with breast cancer. Complement Ther Clin Pract, Vol.13, No.4, pp. 250-257

Wyatt, G. \& Friedman, L.L. (1996). Long term female cancer survivors: quality of life issues and clinical implications. Cancer Nursing, Vol. 19, pp. 1-7

Yabroff, K.R. et al,. (2007). Patient time costs associated with cancer care. JNCI , Vol.99, No.1, pp. 14-23 
Zivian, M. \& Salgado, B. (2007). Side effects revealed: Women's experiences with Aromatase Inhibitors. Breast Cancer Action, San Francisco 


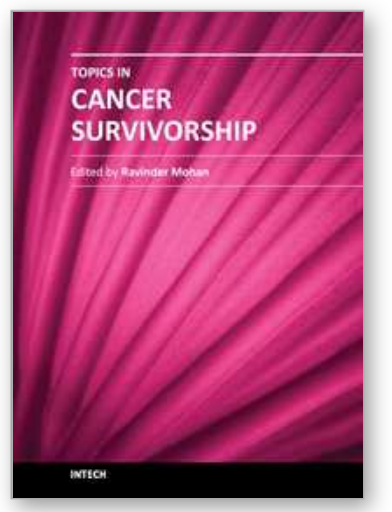

\author{
Topics in Cancer Survivorship \\ Edited by Prof. Ravinder Mohan
}

ISBN 978-953-307-894-6

Hard cover, 290 pages

Publisher InTech

Published online 27, January, 2012

Published in print edition January, 2012

Cancer is now the leading cause of death in the world. In the U.S., one in two men and one in three women will be diagnosed with a non-skin cancer in their lifetime. Cancer patients are living longer than ever before. For instance, when detected early, the five-year survival for breast cancer is $98 \%$, and it is about $84 \%$ in patients with regional disease. However, the diagnosis and treatment of cancer is very distressing. Cancer patients frequently suffer from pain, disfigurement, depression, fatigue, physical dysfunctions, frequent visits to doctors and hospitals, multiple tests and procedures with the possibility of treatment complications, and the financial impact of the diagnosis on their life. This book presents a number of ways that can help cancer patients to look, feel and become healthier, take care of specific symptoms such as hair loss, arm swelling, and shortness of breath, and improve their intimacy, sexuality, and fertility.

\title{
How to reference
}

In order to correctly reference this scholarly work, feel free to copy and paste the following:

Neel Bhuva, Sonia P. Li and Jane Maher (2012). Living With and Beyond Cancer: New Challenges, Topics in Cancer Survivorship, Prof. Ravinder Mohan (Ed.), ISBN: 978-953-307-894-6, InTech, Available from: http://www.intechopen.com/books/topics-in-cancer-survivorship/living-with-and-beyond-cancer-new-challenges

\section{INTECH}

open science | open minds

\section{InTech Europe}

University Campus STeP Ri

Slavka Krautzeka 83/A

51000 Rijeka, Croatia

Phone: +385 (51) 770447

Fax: +385 (51) 686166

www.intechopen.com

\section{InTech China}

Unit 405, Office Block, Hotel Equatorial Shanghai

No.65, Yan An Road (West), Shanghai, 200040, China

中国上海市延安西路65号上海国际贵都大饭店办公楼 405 单元

Phone: +86-21-62489820

Fax: +86-21-62489821 
(C) 2012 The Author(s). Licensee IntechOpen. This is an open access article distributed under the terms of the Creative Commons Attribution 3.0 License, which permits unrestricted use, distribution, and reproduction in any medium, provided the original work is properly cited. 